\title{
Asbestos fibres and man made mineral fibres: induction and release of tumour necrosis factor- $a$ from rat alveolar macrophages
}

\author{
A G Ljungman, M Lindahl, C Tagesson
}

\begin{abstract}
Objectives-Mounting evidence suggests that asbestos fibres can stimulate alveolar macrophages to generate the potent inflammatory and fibrogenic mediator, tumour necrosis factor-alpha (TNF-a), and that this may play an important part in the onset and development of airway inflammation and lung fibrosis due to asbestos fibre inhalation. Little is known, however, about the ability of other mineral fibres to initiate formation and release of TNF-a by alveolar macrophages. Therefore the effects of different fibres (crocidolite, chrysotile A, chrysotile $B$, two man made mineral fibres (MMVF 21 and MMVF 22), a ceramic fibre (RCF 1), and a silicon carbide whisker fibre (SiCwh)) on formation and release of TNF-a by rat alveolar macrophages were examined.
\end{abstract}

Methods-Cells were isolated and incubated at $37^{\circ} \mathrm{C}$ with the different fibres, or with culture medium alone (controls), and the amounts of TNF- $a$ messenger RNA (mRNA) in the cells and TNF-a bioactivity released into the culture medium were measured at different time points.

Results-Significantly $(P<0.05 v$ control) increased amounts of TNF-amRNA were found in cells exposed to crocidolite, chrysotile A, chrysotile B, MMVF 21, RCF 1, or SiCwh for 90 minutes, and significantly ( $P<0.05 v$ control) increased activities of TNF-a were found in the medium of macrophages exposed to crocidolite, chrysotile A, chrysotile $B$, or MMVF 21 for four hours.

Conclusion-These observations suggest that not only natural mineral fibres but also certain man made mineral fibres are able to induce the formation and release of TNF- $a$ by alveolar macrophages in vitro.

\section{(Occup Environ Med 1994;51:777-783)}

Keywords: tumour necrosis factor, fibres, macrophages

It is now well known that inhalation of asbestos fibres can cause inflammatory response and fibrogenic lung disease in humans and experimental animals. ${ }^{1}$ The cellular mechanisms behind these processes have not been clarified in detail, but several studies have indicated that alveolar macrophages play an important part in the onset and development of inflammatory and fibrogenic lung disease through their ability to release inflammatory mediators. ${ }^{2}$ Tumour necrosis factoralpha (TNF- $a)^{3}$ has been pointed out as a mediator of particular interest, because of its wide spectrum of biological activities. The TNF- $a$ augments neutrophil and eosinophil functions, ${ }^{45}$ modulates endothelial cell haemostatic properties and surface antigens, ${ }^{6}$ and stimulates fibroblast growth. ${ }^{7}$ Increased TNF- $a$ release from human alveolar macrophages after exposure to asbestos fibres has been reported ${ }^{8}$; indeed, of a number of factors measured, only TNF- $a$ was raised in response to chrysotile asbestos exposure in vitro. ${ }^{8}$ Similarly, increased production of TNF- $a$ was found in rat alveolar macrophages exposed to chrysotile A in vitro, ${ }^{9}$ and in rat bronchoalveolar leucocytes after in vivo instillation of crocidolite in a rat intratracheal instillation model. ${ }^{10}$ Crocidolite asbestos in vitro also stimulated normal bronchoalveolar lavage leucocytes to release significantly increased amounts of TNF- $a .{ }^{10}$ Moreover, in a murine model of asbestosis, intratracheal instillation of chrysotile A caused increased production of TNF- $a$ from bronchoalveolar cells. ${ }^{11}$ Altogether, these findings suggest that asbestos fibres stimulate alveolar macrophages to produce TNF- $a$, which can be involved in pulmonary inflammation and fibrosis.

The risk of developing lung inflammation and fibrosis due to occupational exposure to most synthetic fibres is generally considered low. ${ }^{12}$ Current in vitro and animal data, however, indicate an increased risk of developing lung inflammation and fibrosis after exposure to certain synthetic fibres. ${ }^{13}$ The three main classes of synthetic (man made) mineral fibres are fibrous glass, rock or slag wool, and refractory ceramic fibres (RCFs). Recent investigations indicate that chronic inhalation of respirable glass fibres in rats results in little or no pathological changes, and that fibrous glass therefore may not represent an important hazard for fibrotic or neoplastic lung disease. ${ }^{14}$ Still, uncertainty remains concerning the toxicity of rock or slag wool and RCFs, and an ongoing concern exists about the safety of silicone carbide whiskers (SiCwh). In our study, we have compared the ability of different asbestos and synthetic fibres to generate TNF- $a$ from rat alveolar macrophages as a potential indicator of their ability to cause pulmonary inflammation and fibrosis. The generation of TNF- $a$ was investigated both at the messenger RNA (mRNA) level, with a 
Table 1 Chemical composition and size of fibres: crocidolite, MMVF 21, MMVF 22, and RCF 1 components (TIMA data) are expressed as \% of oxides; whereas SiCwh components (Tokai Carbon Co data) are expressed as \% of weight (the SiC content was 99\%); chrysotile $A$ and B components (IUCC data) are expressed as \% on a sample basis

\begin{tabular}{|c|c|c|c|c|c|c|c|}
\hline Characteristics & Crocidolite & Chrysotile A & Chrysotile B & $M M V F 21$ & $M M V F 22$ & $R C F 1$ & SiCwh \\
\hline \multicolumn{8}{|l|}{ Component } \\
\hline $\mathrm{SiO}_{2}$ & $50 \cdot 87$ & $39 \cdot 1$ & $38 \cdot 6$ & $46 \cdot 2$ & $38 \cdot 35$ & $47 \cdot 7$ & 0.5 \\
\hline $\mathrm{Al}_{2} \mathrm{O}_{3}$ & 0.05 & 0.6 & $2 \cdot 0$ & $13 \cdot 0$ & $10 \cdot 55$ & $48 \cdot 0$ & 0.08 \\
\hline $\mathrm{Cr}_{2} \mathrm{O}_{3}$ & - & $1 \cdot 0$ & $0 \cdot 2$ & - & - & 0.03 & 0.05 \\
\hline $\mathrm{Fe}_{2} \mathrm{O}_{3}$ & $21 \cdot 41$ & 0.88 & $1 \cdot 14$ & $7 \cdot 00$ & 0.30 & 0.97 & 0.05 \\
\hline $\mathrm{TiO}_{2}$ & 0.01 & 0.01 & 0.03 & 2.95 & 0.45 & $2 \cdot 05$ & - \\
\hline $\mathrm{CaO}$ & 0.71 & 0.05 & 0.1 & 16.9 & $37 \cdot 5$ & 0.07 & 0.05 \\
\hline $\mathrm{MgO}$ & 3.41 & 31 & 32 & $9 \cdot 25$ & 9.9 & 0.08 & 0.02 \\
\hline $\mathrm{Na}_{2} \mathrm{O}$ & $5 \cdot 62$ & 0.05 & 0.01 & $2 \cdot 64$ & $0 \cdot 38$ & 0.54 & - \\
\hline $\mathrm{K}_{2} \mathrm{O}$ & 0.07 & 0.03 & 0.02 & $1 \cdot 25$ & 0.45 & $0 \cdot 16$ & - \\
\hline $\mathrm{MnO}$ & 0.05 & $0 \cdot 8$ & 0.6 & $0 \cdot 16$ & 0.70 & - & - \\
\hline $\mathrm{SO}_{3}$ & $0 \cdot 12$ & - & - & 0.23 & 1.81 & - & - \\
\hline $\mathrm{ZrO}_{2}$ & - & - & - & 0.03 & 0.06 & $0 \cdot 11$ & - \\
\hline SrO & - & - & - & 0.07 & 0.05 & - & - \\
\hline $\mathrm{BaO}$ & - & - & - & 0.04 & 0.04 & - & - \\
\hline $\mathrm{P}_{2} \mathrm{O}_{5}$ & - & - & $0 \cdot 1$ & $0 \cdot 24$ & - & - & - \\
\hline Co & - & 0.08 & 0.07 & - & - & - & 0.05 \\
\hline \multicolumn{8}{|l|}{ Diameter $(\mu \mathrm{m})$ : } \\
\hline Range & $0 \cdot 1-1 \cdot 3$ & - & - & $0 \cdot 2-1 \cdot 3$ & $0.3-3 \cdot 6$ & $0 \cdot 1-3 \cdot 7$ & $0.3-0.6$ \\
\hline Mean (SD) & $0.3(0.2)$ & - & - & $1.3(0.8)$ & $1 \cdot 2(0 \cdot 7)$ & $1 \cdot 1(0 \cdot 8)$ & - \\
\hline \multicolumn{8}{|l|}{ Length $(\mu \mathrm{m})$ : } \\
\hline Range & $1 \cdot 3-30 \cdot 7$ & $0 \cdot 5-80$ & $0 \cdot 5-80$ & $1 \cdot 8-76.9$ & $1 \cdot 1-73 \cdot 2$ & $2 \cdot 3-67 \cdot 9$ & $5-15$ \\
\hline Mean (SD) & $9 \cdot 9(7 \cdot 8)$ & - & - & $24 \cdot 6(19 \cdot 9)$ & $21 \cdot 4(17 \cdot 6)$ & $22 \cdot 4(19 \cdot 0)$ & - \\
\hline
\end{tabular}

TNF- $a$ oligonucleotide probe, and as release of bioactive TNF- $a$ that is, such cytokine release that is considered essential for the development of lung fibrosis.

\section{Methods}

REAGENTS

Chrysotile A, chrysotile $B$, and crocidolite asbestos fibres were International Union Against Cancer (IUCC) standard fibres. ${ }^{15}$ MMVF-21 (rock wool), MMVF-22 (slag wool), and RCF 1 (kaolin ceramic fibre) were provided by Thomas E June, Repository Administrator, TIMA, USA, whereas SiCwh (Silicon carbide whiskers, Tokai 100. Tokai Carbon, Tokyo, Japan) were a gift from Indra Svensson, FOA Umeå, Sweden. Table 1

Figure 1 Microscopic appearance of different fibres after addition to macrophage monolayers. The fibres were: $(A)$ crocidolite; (B) $M M V F$ 21; (C) RCF 1; (D) $\mathrm{SiCwh}$. The amount of fibre was $10 \mu \mathrm{g} / \mathrm{cm}^{2}$ in each case. Original magnification $\times 400$.
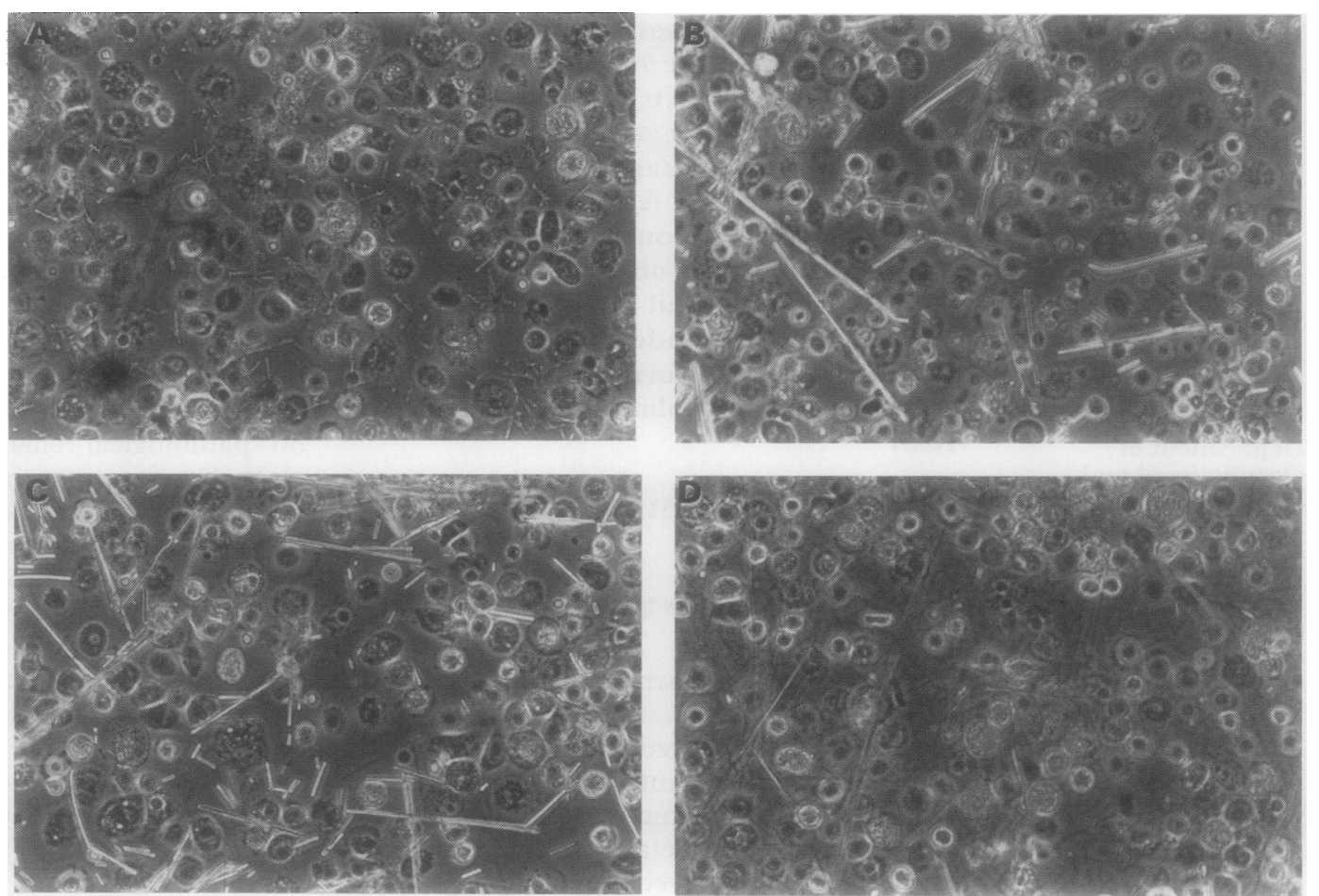

shows the chemical composition of the different fibres and their lengths and diameters. All fibres were suspended in Roswell Park Memorial Institute (RPMI)-1640 medium containing $2 \mathrm{mM}$ L-glutamine and $25 \mathrm{mM}$ $\mathrm{N}$-2-hydroxyethylpiperazine-N-2-ethanesulphonic acid (HEPES) buffer (Flow Laboratories, Irvine, Scotland) and gently sonicated. Standard lipopolysaccharide (LPS, Escherichia coli 0111:B4; Sigma Chemicals, St Louis, MO, USA) was prepared in RPMI1640 medium.

\section{ISOLATION OF ALVEOLAR MACROPHAGES}

Male Wistar rats (200-250 g) were obtained from $B$ and $K$ Universal AB, Sollentuna, Sweden. The animals were derived from a pathogen free colony and housed under 
pathogen free conditions. After anaesthesia with a lethal dose of sodium pentobarbitone the lungs were excised, and bronchoalveolar lavage was performed with $6-8 \mathrm{ml}$ aliquots of a total of $50 \mathrm{ml}$ of ice cold calcium and magnesium free phosphate buffered saline (PBS) containing $0.2 \mathrm{mM}$ ethylene diamine tetraacetate (EDTA). The lavage fluid was centrifuged at $500 \mathrm{~g}$ for 10 minutes, and the cell pellet was washed by resuspending in PBS. The resuspended cells were then pooled, centrifuged again, and resuspended in RPMI1640 medium. Cell number was determined by haemocytometer counting and cell viability by trypan blue exclusion. The viability exceeded $98 \%$. Cell differential countings were performed on cytocentrifuge preparations stained with Wright stain (Accustain, Sigma); the cell suspension consisted of at least $95 \%$ macrophages. Aliquots $(2 \mathrm{ml})$ of the cell suspension containing $2 \times 10^{6}$ cells were plated in $35 \times 10 \mathrm{~mm}$ plastic culture dishes (Falcon Plastics, Oxnard, CA, USA) and incubated at $37^{\circ} \mathrm{C}$ in a humidified atmosphere of $5 \% \mathrm{CO}_{2}$ in air. After one hour, more than $90 \%$ of the cells adhered to the culture dishes. Non-adherent cells were removed by washing twice with RPMI-1640 medium, and new RPMI-1640 medium containing $2 \mathrm{mM}$ L-glutamine and $10 \%$ heat inactivated fetal bovine serum (FBS, Flow), $100 \mathrm{U} / \mathrm{ml}$ of penicillin $\mathrm{G}, 100 \mu \mathrm{g} / \mathrm{ml}$ of streptomycin, and 0.25 $\mu \mathrm{g} / \mathrm{ml}$ of amphotericin B (antibiotic-antimycotic solution, Flow) was added. The macrophage monolayers were then used in fibre exposure experiments.

\section{CELL CULTURE AND FIBRE EXPOSURE}

Standard suspensions $(2 \mathrm{mg} / \mathrm{ml})$ of all fibers were made in RPMI-1640 medium and gently sonicated for 30 seconds. Aliquots $(100 \mu \mathrm{l})$ of these fibre suspensions were then added to the macrophage monolayers. Figure 1 shows typical pictures of fibres and cells as they appeared microscopically. The cells exposed to fibres were incubated for 90 minutes or four hours at $37^{\circ} \mathrm{C}$ in $95 \%$ air and $5 \% \mathrm{CO}_{2}$. Controls-that is, macrophages exposed to medium alone, were incubated in parallel. After incubation, the medium was collected and frozen at $-70^{\circ} \mathrm{C}$ (for not more than two weeks) until analysed for the amount of TNF- $a$ bioactivity. The macrophage monolayers were washed with PBS and then processed for RNA preparation. Cells not used for RNA preparation were assessed for viability by trypan blue exclusion; more than $90 \%$ of the alveolar macrophages were viable in either the presence or absence of fibres. The LPS $(1 \mu \mathrm{g} / \mathrm{ml})$ was included as a positive control and was also used in experiments where fibres $(100 \mu \mathrm{g} / \mathrm{ml})$ and LPS $(1 \mu \mathrm{g} / \mathrm{ml})$ were added together to the cells. All fibre suspensions and culture media contained $<0.5 \mathrm{U}$ endotoxin $/ \mathrm{ml}$ as determined by the Limulus Amebocyte Lysate assay (E-TOXATE, Sigma).

NORTHERN BLOT ANALYSIS

Total cellular RNA from the alveolar macro- phages were isolated by the guanidine isothiocyanate method described by Chomczynski and Sacchi. ${ }^{16}$ Briefly, cells were overlayed with $200 \mu \mathrm{l}$ of a solution consisting of $25 \mathrm{mM}$ sodium citrate, $\mathrm{pH} \mathrm{7,4} \mathrm{M}$ guanidinium thiocyanate, $0.5 \%$ sarkosyl, and $0.1 \mathrm{M} 2$-mercaptoethanol. The plate was then scraped with a rubber policeman and the cell lysate was transferred to an Eppendorf tube and homogenised. After homogenisation, $20 \mu \mathrm{l}$ of

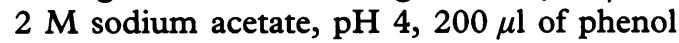
(water saturated), and $40 \mu \mathrm{l}$ of chloroformisoamyl alcohol (49:1) were added sequentially to the homogenate, with thorough mixing after the addition of each reagent. The RNA was precipitated by isopropanol and dissolved in $200 \mu \mathrm{l}$ of the guanidinium thiocyanate solution followed by a second isopropanol precipitation. The extracted RNA was dissolved in diethyl pyrocarbonate (DEPC) treated water. Total RNA recovered from each cell lysate was separated on $2 \cdot 2 \mathrm{M}$ formaldehyde $/ 1 \%$ agarose gels. The RNA was transblotted to nylon filters and UV light immobilised, and the TNF- $a$ mRNA was probed by a ${ }^{32} \mathbf{P}$ 5'-end labelled TNF- $a$ oligonucleotide probe. This murine TNF- $a$ probe was complementary to nucleotides 738 to 767 and had the sequence 5'-GTC-CCCCTT-CTC-CAG-CTG-GAA-GAC-TCCTCC-3'. ${ }^{17}$ The total RNA concentrations in each lane of the gel were assessed by monitoring $\beta$-actin mRNA, with a $\beta$-actin probe complementary to nucleotides 432 to 473 with the sequence 5'-GGC-TGG-GGT-GTT-GAAGGT-CTC-AAA-CAT-GAT-CTG-GGTCAT-CTT-3'.18 The filters were hybridised overnight, washed, and exposed to $x$ ray film (DuPont-Cronex 4) at $-70^{\circ} \mathrm{C}$ with an intensifying screen. The autoradiographs were quantified on a digitised image with a coupled charge device (CCD) camera $(512 \times 512$ pixels) in combination with a computerised imaging 8-bits system (Millipore Biolmage, Ann Arbor, MI, USA). Data were expressed as integrated optical density units (IODs) and used for further calculations.

\section{TNF- $a$ BIOASSAY}

The bioactivity of TNF- $a$ was quantified with the WEHI 164, subclone 13 fibrosarcoma lytic assay. ${ }^{19}$ The WEHI 164, subclone 13 cells were the gift of Dr Terje Espevik (Institute of Cancer Research, University of Trondheim, Trondheim, Norway). The WEHI cells were suspended at a concentration of $5 \times 10^{5}$ cells $/ \mathrm{ml}$ in RPMI-1640 medium with $10 \%$ FBS, $1 \mathrm{mM}$ L-glutamine, and $0.5 \mu \mathrm{g} / \mathrm{ml}$ actinomycin $\mathrm{D}$, and $100 \mu \mathrm{l}$ aliquots were plated in 96 well flat bottom microtitre plates. Before analysis of the conditioned medium it was centrifuged to remove any remaining fibres. The media samples were serially diluted, and $100 \mu \mathrm{l}$ was added to each well. Plates were incubated for 20 hours at $37^{\circ} \mathrm{C}$ in $95 \%$ air and $5 \% \mathrm{CO}_{2}$. This was followed by the addition of $20 \mu \mathrm{l}$ of 3-[4,5dimethylthiazol-2-yl]-2,5-diphenyltetrazolium bromide (MTT, $5 \mathrm{mg} / \mathrm{ml}$; Sigma) and incubation for four more hours. A total of $150 \mu \mathrm{l}$ of 
Table 2 Integrated optical density units (IODs) of TNF- $a$ and $\beta$-actin $m R N A$ in the northern blot (fig 3); the values given were recorded by the BioImager and used for calculation of TNF-a/ $\beta$-actin ratios; these ratios were then calculated as \% of control

\begin{tabular}{lllll}
\hline Fibre & $T N F-a$ & $\beta$-actin & $T N F-a / \beta$-actin & Control (\%) \\
\hline Chrysotile A & 1.987 & 31.135 & 0.064 & 320 \\
Chrysotile B & 2.732 & 35.790 & 0.076 & 380 \\
Crocidolite & 2.198 & 35.664 & 0.062 & 310 \\
MMVF 21 & 0.586 & 22.424 & 0.026 & 130 \\
MMVF 22 & 0.567 & 22.792 & 0.025 & 125 \\
RCF 1 & 0.593 & 19.215 & 0.031 & 155 \\
SiCwh & 1.974 & 33.264 & 0.060 & 300 \\
LPS & 4.257 & 40.658 & 0.105 & 100 \\
Control & 0.337 & 16.815 & 0.020 & \\
\hline
\end{tabular}

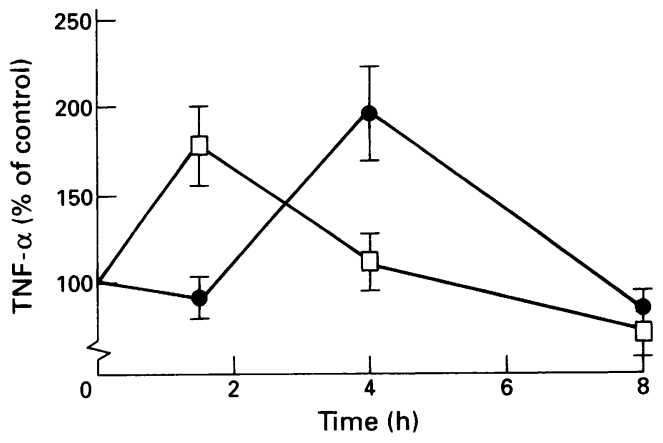

Figure 2 Induction of production of TNF-a in alveolar macrophages by crocidolite fibres. Macrophages were exposed to medium alone (control) or medium containing crocidolite $(100 \mu \mathrm{g} / \mathrm{ml})$. Data are means (SEM) of three to six observations of TNF-a mRNA in the cells ( $\square)$ and TNF-a bioactivity in the medium (๑) at each time point.

supernatant fluid was removed from each well and replaced with $100 \mu \mathrm{l}$ isopropanol-0.04 M $\mathrm{HCl}$ to dissolve the tetrazolium crystals. Culture plates were read in an enzyme linked immunoadsorbent assay (ELISA) reader at $570 \mathrm{~nm}$ with a reference filter at $630 \mathrm{~nm}$. The TNF- $a$ activity was defined with an internal standard of human recombinant TNF (rTNF) with a specific activity of $20 \mathrm{U} / \mathrm{ng}$ protein. One unit of TNF- $a$ activity was defined as the amount required to produce $50 \%$ dead target cells. The rTNF- $a$ preparation used in this study had a specific activity of $2 \times 10^{6} \mathrm{U} / \mathrm{mg}$ protein with the actinomycin D L929 bioassay (Sigma data sheet). When used in the WEHI assay the specific activity of the rTNF- $a$ preparation remained at $2 \times 10^{6} \mathrm{U} / \mathrm{mg}$ protein. The assay was

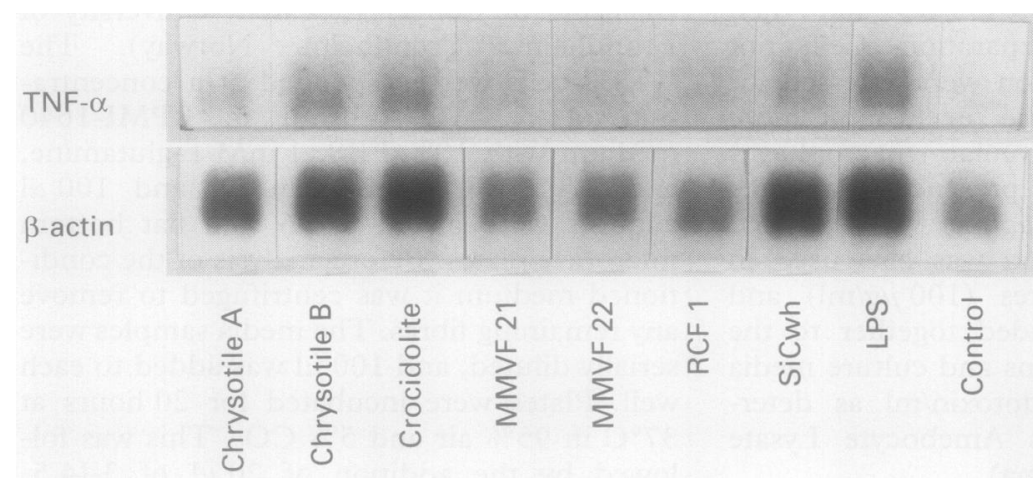

Figure 3 Northern blot analysis of TNF-a mRNA in alveolar macrophages exposed to different mineral fibres for 90 min. The $\beta$-actin $m R N A$ is an internal control for total $R N A$ loading/well. The LPS refers to cells exposed to lipopolysaccharide $(1 \mu \mathrm{g} / \mathrm{ml})$. linear between 1 and 100 units. The within assay variation was $8 \%$.

\section{STATISTICAL ANALYSIS}

All experiments were performed in duplicates and the value from one experiment is the mean of the duplicates. To adjust for variations in baseline TNF- $a$ mRNA and bioactivities between different experiments, the data in each experiment were expressed as percentages of the control value in that specific experiment. Differences between treatments were evaluated with one way analysis of variance and the Mann-Whitney $U$ test. Statistical significance was at $\mathrm{P}<0.05$.

\section{Results}

CROCIDOLITE FIBRE INDUCTION OF TNF- $\alpha$ PRODUCTION OVER TIME

To find out suitable experimental conditions for the study, we first performed experiments where we looked at effects of doses of crocidolite of 10,100 , and $200 \mu \mathrm{g} / \mathrm{ml}$ at various time points and compared them with controlsthat is, alveolar macrophages exposed to medium alone (data not shown). We then found that macrophages exposed to $100 \mu \mathrm{g} / \mathrm{ml}$ of crocidolite showed a significant $(P<0.05 v$ controls) rise in TNF- $a$ mRNA concentrations after 90 minutes of incubation (fig 2). This was followed by a significant $(P<0.05 v$ controls) augmentation in TNF- $a$ bioactivity released to the culture medium after four hours of incubation (fig 2). The TNF- $a$ mRNA had returned to baseline concentrations by four hours. Based on these findings we chose to investigate the effects of all other fibres in the study at a concentration of 100 $\mu \mathrm{g} / \mathrm{ml}$ after 90 minutes and four hours of incubation. The dose of $100 \mu \mathrm{g} / \mathrm{ml}$ of chrysotile $\mathrm{A}$ has previously been used by others to show production of TNF- $a$ in macrophages. ${ }^{11} 20$

\section{EFFECT OF VARIOUS FIBRES ON INDUCTION OF} TNF- $a$ mRNA

To determine whether other fibres than crocidolite had a similar ability to induce increases in synthesis of TNF- $a$ mRNA, we incubated macrophages in the presence of various fibres, or medium alone (control). Figure 3 shows a northern blot analysis of TNF- $a$ mRNA recovered from the cells after 90 minutes of fibre exposure. There were considerable differences in the amounts of mRNA in the different lanes, probably due to variations in the total recovery of mRNA from the different cell lysates. To adjust for these differences, the amount of TNF- $\alpha$ mRNA was divided by the amount of $\beta$-actin mRNA in each case; table 2 shows these data (for the northern blot in fig 3). With such adjusted TNF- $a$ mRNA concentrations, it seemed that not only asbestos, but also other fibres induced increases in synthesis of TNF- $a$ mRNA. A series of experiments showed that chrysotile A, chrysotile B, crocidolite, MMVF 21, RCF 1 , and SiCwh caused significantly $(P<0.05 v$ control) increased synthesis of mRNA after 90 minutes of incubation (table 3, fig 4). The 
Table 3 Induction and release of TNF-a in alveolar macrophages exposed to different mineral fibres (100 $\mathrm{\mu g} / \mathrm{ml})$ : data are given as \% of control (macrophages exposed to medium alone): TNF $m R N A$ in the cells was measured by northern blot technique and TNF bioactivity in the cell supernatants by WEHI assay: LPS refers to cells exposed to lipopolysaccharide $(1 \mu \mathrm{g} / \mathrm{ml})$ : values are means (SEM): numbers of experiments are given in second parenthesis

\begin{tabular}{|c|c|c|c|c|}
\hline \multirow[b]{2}{*}{ Fibre } & \multicolumn{2}{|l|}{$T N F-a m R N A$} & \multicolumn{2}{|l|}{ TNF-a bioactivity } \\
\hline & 90 minutes & Four hours & 90 minures & Four hours \\
\hline $\begin{array}{l}\text { Chrysotile A } \\
\text { Chrysotile B } \\
\text { Crocidolite } \\
\text { MMVF 21 } \\
\text { MMVF 22 } \\
\text { RCF 1 } \\
\text { SiCwh } \\
\text { LPS }\end{array}$ & $\begin{array}{l}188(54)(3)^{\star} \\
223(53)(3)^{\star} \\
178(22)(4)^{\star \star} \\
139(16)(3)^{\star} \\
116(33)(3) \\
160(16)(3)^{\star} \\
151(20)(3)^{\star} \\
416(133)(4)^{\star \star}\end{array}$ & $\begin{array}{l}151(20)(5)^{\star \star} \\
79(18)(4) \\
112(16)(6) \\
102(10)(5) \\
98(14)(5) \\
83(20)(5) \\
121(18)(5) \\
525(64)(5)^{\star \star}\end{array}$ & $\begin{array}{l}85(12)(3) \\
76(13)(3) \\
93(12)(5) \\
79(11)(3) \\
84(18)(3) \\
97(22)(3) \\
81(20)(3) \\
334(154)(3)^{\star}\end{array}$ & $\begin{array}{l}315(66)(6)^{\star \star} \\
218(34)(4)^{\star \star} \\
196(27)(5)^{\star \star} \\
220(29)(4)^{\star} \\
192(39)(4) \\
189(69)(4) \\
162(28)(4) \\
746(90)(3)^{\star \star}\end{array}$ \\
\hline
\end{tabular}

${ }^{\star} \mathrm{p}<0.05 ;{ }^{\star \star} \mathrm{p}<0.01 v$ control.

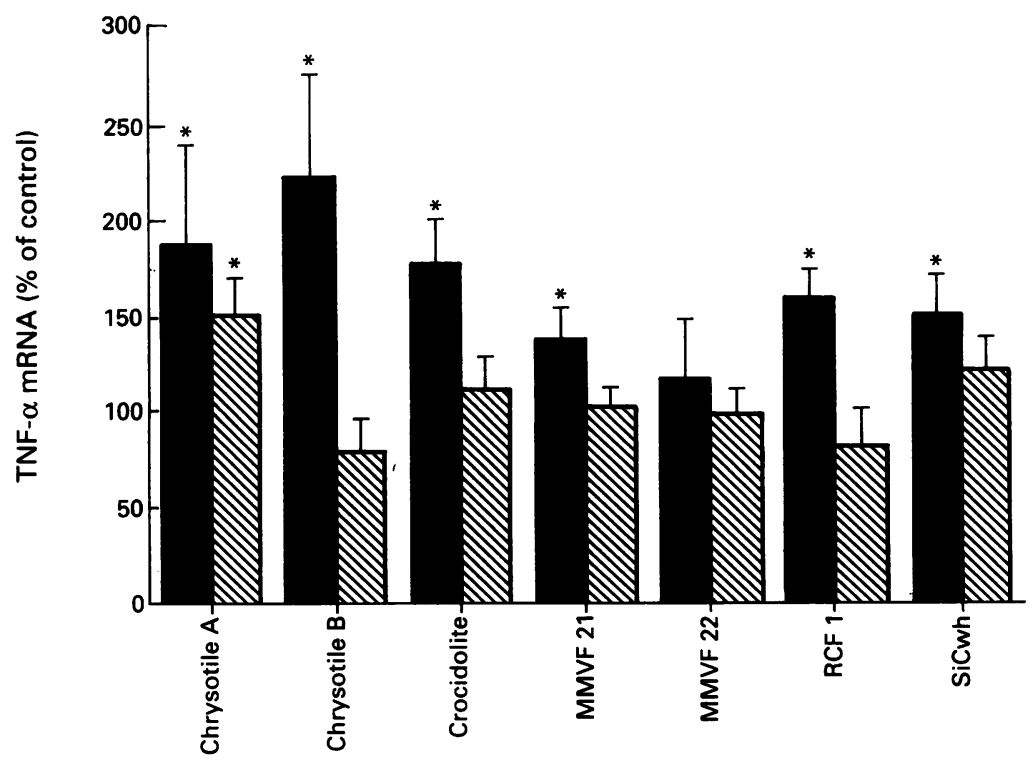

Figure 4 Induction of synthesis of TNF-a mRNA in alveolar macrophages exposed to different mineral fibres after 90 minutes $(\mathbb{D})$ and four hours $(\mathbb{\mathbb { N }})$. Macrophages were exposed to medium alone (control) or medium containing mineral fibres $(100 \mu \mathrm{g} / \mathrm{ml})$. Recorded concentrations were adjusted for total $R N A$ loading with $\beta$-actin $m R N A$ as a measure of total RNA. Data represent means of at least three observations at each time point; vertical bars indicate SEMs. $P<0.05 v$ control.

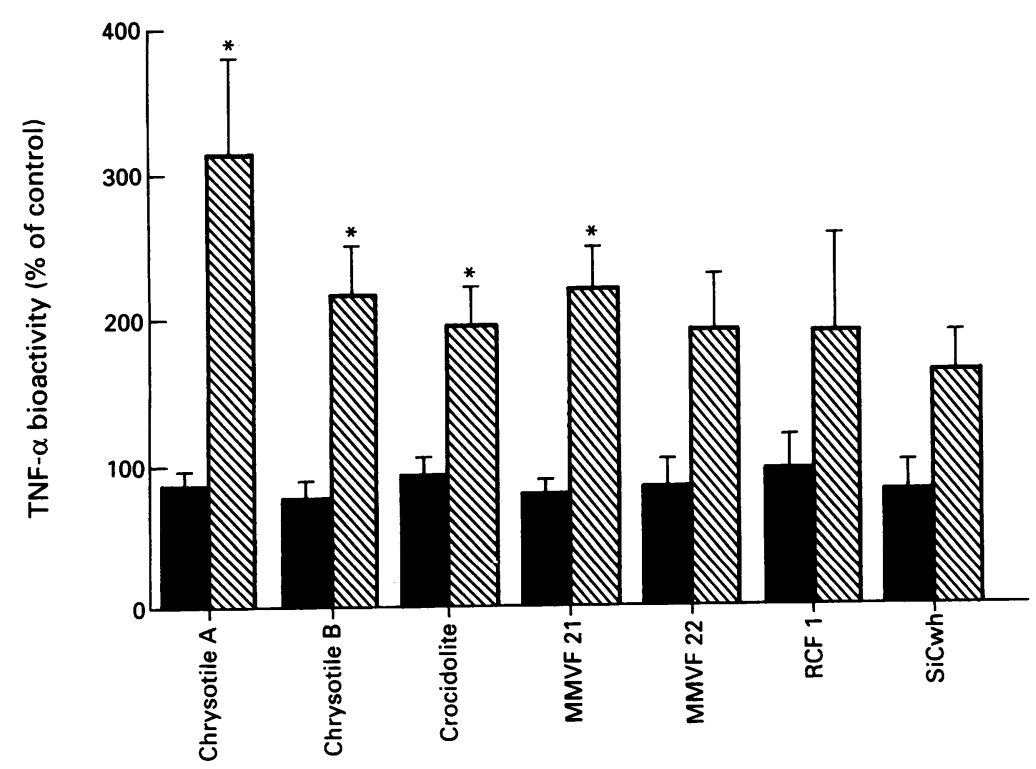

Figure 5 Stimulation of $T N F-a$ production in alveolar macrophages exposed to different mineral fibres after 90 minutes $(\mathbb{0})$ and four hours $(\mathbb{N})$. Macrophages were exposed to medium alone (control) or medium containing mineral fibres $(100 \mu \mathrm{g} / \mathrm{ml})$. Data represent means of at least three observations at each time point; vertical bars indicate SEMs. $P<$ $0.05 v$ control.
LPS $(1 \mu \mathrm{g} / \mathrm{ml})$ was used as a positive control and caused significant increases in TNF- $a$ mRNA both at 90 minutes and four hours ( $P$ $<0.05 v$ controls; table 3 ). The mRNA had returned to baseline concentrations (except for chrysotile A and LPS) after four hours of incubation. In experiments where the cells were incubated with both LPS $(1 \mu \mathrm{g} / \mathrm{ml})$ and chrysotile A or crocidolite $(100 \mu \mathrm{g} / \mathrm{ml})$, we found no augmentation of the mRNA concentrations compared with cells stimulated with LPS alone (data not shown).

EFFECT OF VARIOUS FIBRES ON TNF- $a$ RELEASE To investigate whether the augmented TNF- $a$ mRNA formation also led to enhanced protein synthesis and release, we measured TNF$a$ bioactivity in the medium. To adjust for variations in baseline TNF- $a$ between different experiments (control values ranged from 4-60 U of TNF- $a$ released $/ 10^{6}$ cells), the data in each experiment were expressed as percentages of the control value in that specific experiment. Although there were considerable variations in the absolute bioactivity of TNF- $a$ in different experiments, we found that chrysotile A, chrysotile $B$, crocidolite, and MMVF 21 induced significant increases $(\mathbf{P}<0.05 v$ controls) in TNF- $a$ bioactivity at four hours of incubation (table 3, fig 5). At 90 minutes of exposure we found no increase in the bioactivity. The LPS $(1 \mu \mathrm{g} / \mathrm{ml})$ caused significant increases in TNF- $a$ activity both at 90 minutes and four hours $(\mathbf{P}<0.05 v$ control). The augmentations in TNF- $a$ bioactivity released was $189 \%$ for RCF1 and $162 \%$ of the control for $\mathrm{SiCwh}$ (NS; table 3, fig 5).

\section{Discussion}

There is ample evidence for a close association between asbestos exposure and pulmonary diseases, including mesothelial tumours of the pleura, pulmonary carcinoma, and fibrosis of the lung. Much less is known about the relation between man made mineral fibres and pulmonary diseases. Recent reviews on the health effects of man made mineral fibres have stated that the risk for lung cancer, mesothelioma, or fibrosis after industrial exposure to most glass fibre products is low or negligible, but that more concern is required about the more durable rock wools, slag wools, and ceramic fibres. ${ }^{12}$ The possibility that certain man made fibres might promote airway inflammation and lung fibrosis should thus not be entirely overlooked.

Previous studies have shown that chrysotile A $(20-100 \mu \mathrm{g} / \mathrm{ml})$ is able to stimulate both human and rat alveolar macrophages to produce TNF- $a$ in a time and dose-dependent manner. ${ }^{8920}$ Thus, Bissonnette et al found a threefold increase in TNF- $a$ production from rat alveolar macrophages adhered to microtitre wells after two hours of incubation with chrysotile A $(50 \mu \mathrm{g} / \mathrm{ml}){ }^{20}$ Dubois et al also showed that almost all TNF- $a$ was extracellular and that LPS $(5 \mu \mathrm{g} / \mathrm{ml})$ induced four times as much TNF- $a$ as did chrysotile A. ${ }^{9}$ 
Similar results as for chrysotile $\mathrm{A}$ have been reported after exposure to crocidolite. ${ }^{1021}$ These findings are in accordance with our investigation, in which chrysotile A (100 $\mu \mathrm{g} / \mathrm{ml}$ ) caused a threefold increase ( $v$ control) in production of TNF- $a$ after four hours of exposure, and crocidolite a twofold increase (table 3). Also, significant production of TNF- $a$ (twofold increase $v$ control) was found after exposure to chrysotile B.

Our study also shows that the asbestos induced production of TNF- $a$ was preceded by a significant increase of the TNF- $a$ mRNA concentrations in the cells. This strongly suggests that the increase in production of TNF- $a$ was not due solely to release of preformed TNF- $a$, but that the exposure to asbestos caused increased transcription of the TNF- $a$ gene and subsequent protein synthesis. Increased TNF- $\alpha$ bioactivity was found after four hours of incubation, whereas increased TNF- $a$ mRNA was found after only 90 minutes. The increases in TNF- $a$ mRNA were transient, and returned to control concentrations after four hours of incubation (except in the case of chrysotile A). This could be explained by the action of a unique ribonuclease, degrading mRNAs with sequences rich in adenosine and uridine. ${ }^{22}$ The induction of such a ribonuclease by the same external stimuli that cause formation of TNF- $a$ mRNA may be implicated as a protective mechanism. ${ }^{22}$ It is possible that, in the case of chrysotile $\mathrm{A}$, the sustained increase in TNF- $a$ mRNA after four hours of incubation (and the pronounced formation of TNF- $a$ at that time) was due to less activation of this ribonuclease. Alternatively, the differences between different fibres may be related to their ability to release prostaglandin $E_{2}$, which is known to suppress expression and bioactivity of TNF- $a$ mRNA. ${ }^{23}$ Although the detailed mechanisms remain to be elucidated, our results clearly indicate that various asbestos fibres (chrysotile $A$, chrysotile $B$, and crocidolite) stimulate the formation of TNF- $a$ mRNA and ensuing release of TNF- $a$ by alveolar macrophages.

As well as the asbestos fibres, several man made fibres-a rock wool (MMVF 21), a ceramic fibre (RCF 1), and a silicon carbide whisker (SiCwh)-all caused significant increases in TNF- $a$ mRNA after 90 minutes of incubation (table 3). As with crocidolite and chrysotile $B$, the increase in TNF-a mRNA were transient and control concentrations were reached after four hours of incubation. Unlike the situation with the asbestos fibres, significantly increased TNF- $a$ bioactivity after four hours was found only after incubation with MMVF 21. This might indicate that measurements of TNF- $\alpha$ mRNA are more sensitive to detect the induction of TNF- $a$ than are measurements of TNF- $a$ bioactivity. These findings suggest that not only asbestos fibres, but also certain man made fibres are able to stimulate the formation of TNF- $a$ by alveolar macrophages.

The finding that some fibres seemed more liable than others to stimulate production of TNF- $a$ needs further examination. The differ- ent fibres were compared by examining the effect of a certain quantity of fibres; thus, no effort was made to compare equal numbers of fibres. Hence, it remains to be investigated which fibres would be most prone to stimulate production of TNF- $a$ on a fibre number basis. The microscopic examination showed that the number of fibres were clearly highest in the case of $\mathrm{SiCwh}$ and lowest in the cases of MMVF 21, MMVF 22, and RCF 1, with the asbestos fibres in between. The stimulation of TNF- $a$ seen with MMVF 21 and RCF 1 can therefore not be explained by larger numbers of fibres in these cases. Further investigations must be carried out to clarify the mechanisms by which different fibres may stimulate production of TNF- $a$.

Our results suggest that even a short exposure (two to four hours) of macrophages to fibres is sufficient to stimulate the production of TNF- $a$. Brody et al showed that as little as one hour of exposure to chrysotile is enough to cause a fibroproliferative response in the airways of rats. ${ }^{24}$ The increased production of TNF- $a$ may contribute to this response. The quantity of TNF- $a$ released was within the range of $50-500 \mathrm{U} / \mathrm{ml}$, which accords well with previously reported concentrations for high doses of chrysotile A. ${ }^{9}$ Interestingly, this corresponds to the dose of TNF- $a$ that exerts maximal growth stimulating activity on human fibroblasts. ${ }^{\text {? }}$

Due to variations in the absolute amounts of TNF- $a$ in the different experiments the data were expressed as percentages of the control value in each experiment. The reason for this variation is unclear. Even although we were not able to detect any LPS in the fibre suspensions or in the medium, we cannot exclude the possibility that small amounts of LPS were present and that this could have contributed to the TNF- $a$ found in both unstimulated and stimulated cells. Nevertheless, the macrophages were still able to produce significantly more TNF- $a$ after stimulation with $1 \mu \mathrm{g} / \mathrm{ml}$ of LPS, implying that there was less than maximal stimulation of production of TNF- $a$ caused by endotoxin in the medium.

We have thus obtained some evidence to indicate that not only natural mineral fibres but also certain man made mineral fibres are able to induce the formation and release of TNF- $a$ by alveolar macrophages in vitro. The biological implications of this finding are unclear. Recently, a ceramic aluminium silicate fibre (as well as chrysotile A) was found to stimulate the formation of TNF- $a$ by rat alveolar macrophages in vitro after exposure to cigarette smoke in vivo, ${ }^{25}$ and rock wool has previously been shown to act synergistically with cigarette smoke to cause oxidant mediated damage to DNA. ${ }^{26}$ Moreover, intratracheal instillation of silicon carbide whiskers in rats seems to cause chronic inflammation with increased numbers of macrophages and neutrophils. ${ }^{27}$ Altogether, these findings point to the possibility that several man made fibres may act as inflammatory agents in the respiratory tract. The reasons why some fibres may 
be more inflammatory than others remain unresolved. Also, it should be emphasised that the results of our investigation are based on investigations in vitro and that further studies in vivo are needed to examine the potentially toxic effects of man made mineral fibres.

We thank Dr P Leanderson for helpful suggestions and valuable discussions. This work was supported by the Swedish Work Environment Fund $(91-0241)$.

1 Craighead JE, Mossman BT. The pathogenesis of asbestos-associated disease. $N$ Engl ff Med 1982;306: 1446-55.

2 Lemaire I, Beaudoin H, Masse S, Grondin C. Alveolar macrophage stimulation of lung fibroblast growth in asbestos-induced pulmonary fibrosis. Am $\mathcal{F}$ Pathol 1986; 122:205-11.

3 Carswell EA, Old LJ, Kassel RL, Green S, Fiore N, Williamson B. An endotoxin-induced serum factor that causes necrosis of tumors. Proc Natl Acad Sci USA 1975; 72:3666-70.

4 Klebanoff SJ, Vadas MA, Harlan JM, Sparks LH, Gamble JR, Agosti JM, Waltersdorph AM. Stimulation of JR, Agosti JM, Waltersdorph AM. Stimulation of
neutrophils by tumor necrosis factor. F Immunol 1986;
$136: 4220-5$.

5 Silberstein DS, David JR. Tumor necrosis factor enhances eosinophil toxicity to Schistosoma mansoni larvea. Proc Natl Acad Sci USA 1986;83:1055-9.

6 Nawroth P, Stem DM. Modulation of endothelial cell hemostatic properties by tumor necrosis factor. $\mathcal{f}$ Exp Med 1986;163:740-5.

7 Vilcek J, Palombella VJ, Henriksen-DeStefano DE, Swenson C, Feinman R, Hirai M, Tsujimoto M. Fibroblast growth enhancing activity of tumor necrosis factor and its relationship to other polypeptide growth factors. and its relationship to other poly $1986 ; 163: 632-43$.

8 Perkins RC, Scheule RK, Hamilton R, Gomes G, Freidman G, Holian A. Human alveolar macrophage cytokine release in response to in vitro and in vivo cytokine release in response to in vitro and
asbestos exposure. Exp Lung Res 1993;19:55-65.

9 Dubois CM, Bissonnette E, Rola-Pleszczynski $M$ Asbestos fibers and silica particles stimulate rat alveola macrophages to release tumor necrosis factor. $A m$ Rev Respir Dis 1989;139:1257-64.

$10 \mathrm{Li} \mathrm{XY,} \mathrm{Lamb} \mathrm{D,} \mathrm{Donaldson} \mathrm{K.} \mathrm{The} \mathrm{production} \mathrm{of} \mathrm{TNF-a}$ and Il-1 like activity by bronchoalveolar leucocytes after intratracheal instillation of crocidolite asbestos. Int $f$ Exp Pathol 1993;74:403-10.

11 Bissonnette E, Rola-Pleszczynski M. Pulmonary inflammation and fibrosis in a murine model of asbestosis and silicosis. Inflammation 1989;13:329-39.
12 Lippman M. Man-made mineral fibers (MMMF): human exposures and health risk assessment. Toxicol Ind Health 1990;6:225-46.

13 Wheeler CS. Exposure to man-made mineral fibers: a summary of current animal data. Toxicol Ind Health 1990;6:293-307.

14 Hesterberg TW, Miiller WC, McConnell EE, Chevalier J, Hadley JG, Bernstein DM, et al. Chronic inhalation toxicity of size-separated glass fibers in Fischer 344 rats. Fundam Appl Toxicol 1993;20:464-76.

15 Timbrell V. Characteristics of the International Union Against Cancer standard reference samples of asbestos. In: Shapiro HA, ed. Pneumoconiosis. Proceedings of the In: Shapiro HA, ed. Pneumoconiosis. Proceedings of the International Conference, Fohannesburg, Cap
Oxford: Oxford University Press, 1970, 28-36

16 Chomczynski P, Sacchi N. Single-step method of RNA isolation by acid guanidinium thiocyanate-phenolchloroform extraction. Anal Biochem 1987;162:156-9.

17 Pennica D, Hayflick JS, Bringman TS, Palladino MA Goeddel DV. Cloning and expression in Escherichia coli, of the CDNA for murine tumor necrosis factor. Proc Nat Acad Sci USA 1985;82:6060-4.

18 Tokunaga $K$, Taniguchi $H$, Yoda $K$, Shimizu $M$ Sakiyama $S$. Nucleotide sequence of a full-length cDNA for mouse cytoskeletal beta-actin mRNA. Nucleic Acids Res 1986;14:2829-9.

19 Eskandari MK, Nguyen DT, Kunkel SL, Remick DG. Wehi 164 subclone 13 assay for TNF: sensitivity, speciWehi 164 subclone 13 assay for TNF: sensitivity, speci-
ficity, and reliability. Immunol Invest 1990;19:69-79.

20 Bissonnette E, Carre B, Dubois C, Rola-Pleszczynski M. Inhibition of alveolar macrophage cytotoxicity by asbestos: possible role of prostaglandins. f Leuko Biol 1990;47:129-34.

21 Rosenthal GJ, Stranahan III RP, Fort MM, Luster MI. The role of alveolar macrophage activation in the response to mineral fibers. NATO ASI Series 1989 H30:329-35.

22 Kelley J. Cytokines of the lung. Am Rev Respir Dis 1990; 141:765-88.

23 Spengler RN, Spengler ML, Strieter RM, Remick DG, Larrick JW, Kunkel SL. Modulation of tumor necrosis factor-alpha gene expression. Desensitization of prostaglandin $\mathrm{E}_{2}$-induced suppression. $\mathcal{F}$ Immunol 1989; glandin $\mathrm{E}_{2}-\mathrm{i}$

24 Brody AR, Hill LH, Adkins B Jr, O'Connor RW. Chrysotile asbestos inhalation in rats: deposition pattern and reaction of alveolar epithelium and pulmonary macrophages. Am Rev Respir Dis 1983;128:670-9.

25 Morimoto Y, Kido M, Tanaka I, Fujino A, Higashi T Yokosaki Y. Synergistic effects of mineral fibres and cigarette smoke on the production of tumour necrosis factor by alveolar macrophages of rats. $\mathrm{Br} F$ Ind Med 1993;50:955-60.

26 Leanderson P, Tagesson C. Cigarette smoke potentiates the DNA-damaging effect of manmade mineral fibers. Am $\mathcal{F}$ Ind Med 1989;16:697-706.

27 Vaughan GL, Trently SA, Wilson RB. Pulmonary response, in vivo, to silicon carbide whiskers. Environ Res 1993;63:191-201. 